\title{
Natureza e melancolia: uma leitura de $A$ menina morta e Repouso de Cornélio Penna
}

\author{
Guilherme Zubaran de Azevedo, UFMG
}

Resumo: O trabalho tem como objetivo analisar a presença da natureza nos romances A menina morta e Repouso de Cornélio Penna. O enfoque se baseia na perspectiva segundo a qual essas duas obras narram eventos violentos e traumáticos relacionados com o declínio do mundo patriarcal. Assim, a decadência do patriarcalismo é representada na natureza que aparece em estado de abandono. Nesse sentido, há um olhar narrativo melancólico pelo qual a espacialidade adquire uma dimensão humana, na medida em que a sua decadência evidencia o declínio do sistema social e econômico da família patriarcal.

Palavras-chave: Cornélio Penna; natureza; melancolia.

Analisar as manifestações da natureza nas obras de Cornélio Penna implica delimitar preliminarmente algumas questões importantes: em primeiro lugar, o horizonte teórico e interpretativo se baseia nas reflexões a respeito da violência e do trauma na literatura brasileira; num segundo momento, a noção de natureza refere-se à perspectiva, de um lado, sobre a espacialidade do mundo rural, no Brasil, e, de outro, sobre os papéis sociais definidos na experiência da família patriarcal; por fim, o estudo focaliza o terceiro e o último romance escritos por Cornélio Penna.

Pensar a história política e social do Brasil a partir da presença da violência, conforme a hipótese de Jaime Ginzburg ${ }^{1}$, constrói um olhar a respeito da literatura baseado na dicotomia do trauma e da melancolia. Esses dois elementos configuram um tipo de forma literária marcada por um descentramento e uma espessura temporal.

O evento traumático diz respeito a uma situação limite, caracterizada por um excesso de realidade que se choca com a capacidade de percepção ou recepção do sujeito. Esse real traumático, de acordo com Seligmann-Silva ${ }^{2}$, é compreendido como uma ferida capaz de desestabilizar as condições da consciência e da memória de um sujeito, cuja enunciação sofre um processo de limitação, tornando problemática a própria representação da realidade violenta: "Tanto o sujeito é colocado diante de suas próprias insuficiências, como o objeto, a realidade observada, se desordena"3. Portanto, há um elemento lacunar calcado na incapacidade de uma recordação total do fato, visto que este é da ordem do inenarrável e do indizível, isto é, diante de uma experiência de extrema violência, a língua se torna insuficiente para representá-la.

Em torno desse quadro teórico, pode-se analisar a manifestação da natureza na prosa de Cornélio Penna, cuja obra, composta de quatro romances (Fronteira, Dois romances de Nico Horta, Repouso e A menina morta), é publicada, entre as décadas de 1930 e 1950, período marcado por uma série de mudanças políticas e econômicas que acarretaram um processo de modernização da sociedade brasileira.

Os seus romances se estruturam pelo ângulo da memória, na medida em que narram momentos históricos do passado nacional, localizados na virada do século XIX para o $\mathrm{XX}$. No entanto, a historicidade presente nas narrativas não evoca o contexto social de 
forma totalizante, ou seja, não há uma representação completa da vida nacional da época; ao contrário, o papel mnemônico repousa na fragilidade, como explica Jeanne Marie Gagnebin ${ }^{4}$, dos rastros do passado que se articulam num jogo entre recordar e esquecer. Esse processo se estabelece a partir da irrupção dos vestígios de épocas pretéritas no momento da enunciação, quebrando a linearidade temporal e unindo os momentos históricos de modo coordenativo e, consequentemente, não hierárquico ${ }^{5}$.

Dessa maneira, os romances de Cornélio Penna apresentam reminiscências da vida pretérita do mundo patriarcal. Na verdade, são pequenos relampejos ou intermitências que revelam experiências do patriarcalismo relacionadas com situações de violência e trauma por meio das quais as vozes emudecidas encontram um canal de enunciação. A natureza é encenada como vestígios e rastros que evidenciam as marcas exploratórias desse sistema social.

As recordações se estruturam na narrativa do romance $A$ menina morta por meio de uma configuração textual que privilegia, de acordo com Georg Otte ${ }^{6}$, a verticalidade da experiência - ao contrário da horizontalidade presente na narrativa tradicional - que é elaborada em capítulos fragmentados. Portanto, os sentimentos, latentes e reprimidos sob a presença da menina, são liberados após a sua morte, de maneira que o romance os configura em capítulos extremamente verticais que não possuem um fio capaz de amarrálos em um continuum. Daí, então, a capacidade que o romance tem de narrar a complexidade dos conflitos travados no interior do mundo familiar.

No livro A menina morta, publicado em 1954, a história narra o cotidiano de uma família tradicional que vive na grande fazenda produtora de café chamada de Grotão. Assim, essa propriedade rural se constitui no palco onde se desenvolvem os dramas ligados às vivências das mulheres agregadas, das escravas, dos escravos e dos senhores. No início da história, o narrador acompanha o personagem do Comendador, senhor e patriarca da família, que passeia a cavalo pelos campos da propriedade, vistoriando o trabalho dos escravos. Nesse primeiro momento, a entrada da fazenda é descrita como uma espécie de palácio imperial:

As árvores estavam pesadas de folhagens e de parasitas que se curvavam sobre a estrada, debruçando-se de tal forma que havia ali espesso caramanchão, interminável túnel verde opulento de flores coloridas, e em todo ele reinava a meia-luz roxa entremeada de amarelo do sol coado pelos galhos, emaranhados em gestos de braços amigos. (...). Os claros-escuros da abóboda assim formados, em claustro sem fim, apoiado nas colunas das árvores em dórico severo, davam qualquer coisa de irreal a tudo, naquela manhã, que só mesmo a natureza sabe dar, quando imita a si mesma, para disfarçar a sua verdade demasiado rica e forte ${ }^{7}$.

A construção da narrativa da entrada do Grotão se compõe de alguns elementos marcantes dos romances de Cornélio Penna: primeiro, há um traço realista que se manifesta no detalhamento do cenário e dos objetos, delineando a presença das árvores sobre a estrada; e em segundo lugar, os traços do Expressionismo e do Barroco, apontados pela fortuna crítica, se expressam, de um lado, na acentuação das cores - como o amarelo, o roxo e o verde - e, de outro, na figura do claro-escuro - no jogo de luz e sombra - que desenha uma natureza hiperbólica, cheia de expressividade.

Nessa altura da narrativa, a propriedade metaforiza uma visão da natureza grande, veiculada, primeiramente, pelos escritores do Romantismo no século XIX. De acordo com Antônio Candido ${ }^{8}$, esses autores relacionam a grandeza da pátria como um 
desdobramento da exuberância da paisagem brasileira. O caráter hiperbólico da paisagem do Grotão repousa no fato de que, nesse capítulo, o narrador focaliza os passos do senhor pelos seus campos:

Era dono do Grotão, de volta de sua quotidiana ronda pelos principais pontos de trabalho da propriedade, e tudo se animava à sua paisagem, de cada lado das estradas. Mesmo de longe distinguiam o ruído inconfundível dos cascos de seu cavalo, e imediatamente os negros redobravam os golpes de enxadas e das foices, excitados pelas exclamações de encorajamento dos feitores e capatazes, e o trabalho atingia seu paroxismo quando ele chegava perto e se detinha por alguns instantes. ${ }^{9}$

Era a atenção solícita do Senhor, a presença paternal que os mantinha sempre em saúde, a fim de ser conseguido o rude vigor que se esperava deles. Mas a terra respondia generosamente aos seus esforços, e abria-se sempre em riquezas inesgotáveis, na fartura que os irmanava no total sentimento de pujança. ${ }^{10}$

Essas duas passagens evidenciam que o narrador, focalizando a figura do patriarca, assume o discurso da esfera do poder a fim de legitimar o trabalho escravo e a idéia de uma natureza farta e pujante. Há uma organicidade, nos dois trechos citados, entre os elementos - natureza, escravos e senhor -, de maneira a construir uma imagem homogênea da nação brasileira, cuja potencialidade se baseia na riqueza do seu espaço natural, na força da sua mão-de-obra escrava e na potência dos seus homens de poder.

A perspectiva de uma nacionalidade orgânica indica a introdução da temporalidade dos proprietários na narrativa, cuja marca realista se relaciona com certa harmonia presente nos dois trechos, já que os escravos aceitam passivamente a sua condição diante do Senhor. Além disso, o Comendador é caracterizado pelo narrador como um senhor feudal sul-americano, o que reforça a aura do seu poder vinculado à formação colonial que se baseia, segundo Sérgio Buarque de Holanda ${ }^{11}$, de um lado, no familismo e, de outro, na herança rural.

No entanto, na sequência da história, os sinais de decadência contaminam as relações sociais e a empresa latifundiária. É importante observar que, ao longo do século XIX, o patriarcalismo rural, elemento central na colonização do Brasil, sofre um processo de declínio econômico na medida em que a urbanização e uma pequena burguesia avançam na sociedade da época ${ }^{12}$. Em um diálogo entre o Comendador e o seu veterinário, pode-se identificar a presença dessa crise econômica na fala deste:

[...] vim parando pelas fazendas de meus clientes e amigos, e por isso deixei a corte há mais de seis meses... mas não creio que depois disso se tenha passado nada de novo. A grande crise já não serve mais de assunto nas conversas da rua do Ouvidor ${ }^{13}$.

Gilberto Freyre aponta uma oposição campo/cidade, durante o século XIX, sobretudo com a ascensão de um patriarcado urbano e com o declínio material das grandes fazendas monocultoras e escravocratas, sobretudo em função de técnicas agrícolas rudimentares e predatórias e do encarecimento da mão-de-obra escrava.

A decadência econômica se mescla à crise do mundo familiar, englobando aí a autoridade paterna, o dispositivo do favor e a escravidão. Isto ocorre a partir da morte da menina, filha mais nova do casal de proprietários, que libera uma série de sentimentos, anteriormente recalcados pela sua presença mítica, relativos aos sofrimentos das 
mulheres agregadas, dos escravos e escravas, instaurando a historicidade que conduzirá o Grotão ao declínio: "havia um princípio de desagregação, de ruína e desmoronamento que todos suspeitavam, e olhavam para o dono da casa como o único capaz de salvá-los" 14. O princípio de degradação se agrava à medida que se desenvolve a narrativa, frustrando a esperança do restabelecimento da ordem em razão da morte do Comendador. A presença da personagem Carlota, filha mais velha do casal, representa mais outro fator de desagregação, uma vez que ela não substitui a sua irmã no círculo atemporal do mito e rompe com a ordem escravista libertando os escravos.

Outro elemento importante nessa última citação diz respeito ao termo ruína. Palavra chave na teoria da alegoria de Walter Benjamin, a ruína implica a introdução da história cujo sentido aponta para a transitoriedade e a caducidade das coisas. Fragmento que contém um potencial significativo, a ruína concentra uma temporalidade e uma espacialidade do Grotão capaz de revelar resíduos desse sistema exploratório que permanecem no presente da enunciação. Essa relação entre decadência e ruína se concretiza nos últimos capítulos de A menina morta, momento em que a experiência do mundo patriarcal entra em colapso, sobrando apenas os restos da catástrofe que representou tal sistema:

Com esforço conseguiu andar e seus vestidos varreram o caminho, como um grande manto que se arrastasse pelo chão, despedaçando-se nas pontas das pedras e nos espinhos das moitas, e deixavam atrás de si farrapos negros, salpicados de pequeninas frutas selvagens e rubras semelhantes a gotas de sangue... Entretanto, ergueu a cabeça, e todo o seu corpo vibrou com surda e irreprimível alegria e a convicção inescrutável de que espalhava a morte e a ruína em torno dela. ${ }^{15}$

Parecia-lhe agora que em seu luto onde se reuniam tantas recordações mortais, lançava também irremediável maldição sobre a terra pisada e varrida por seus crepes, (...). Olhava com triste prazer o caminho áspero e cheio de flores mortas que se engolfam sob os seus pés e erma por eles esmagadas, e sentia bem que elas eram o sinal bem certo do abandono em que tudo caíra. ${ }^{16}$

Essa citação se contrapõe ao primeiro trecho que narra o passeio do Comendador pelos campos. Nesse sentido, a natureza exuberante e hiperbólica cede lugar a uma espacialidade abandonada e decadente. Nos capítulos finais do romance, o narrador focaliza a perspectiva de Carlota, cujo olhar vislumbra - tal como o anjo benjaminiano da nona tese sobre a história - os escombros e ruínas da propriedade de sua família, espalhados pelos seus pés. A fazenda também se constitui como metáfora e metonímia da nação brasileira ${ }^{17}$, na medida em que concentra a catástrofe, o fracasso e os conflitos de um projeto social baseado na exploração, submissão e violência. Portanto, o Grotão torna-se um lugar de memória, visto que guarda - como afirma Mario de Andrade a respeito do mobiliário em Cornélio Penna - as marcas de uma dimensão humana relacionada com as tensões e os combates de gênero, de raça e de classe que se desenrolaram nesse ambiente.

Há outro aspecto que articula essa última passagem com a nona tese da história de Benjamin: o progresso. Implícito em toda narrativa de Cornélio Penna, o progresso refere-se, de uma parte, às mudanças políticas, econômicas e, de outra parte, à visão do grupo de escritores, que iniciam suas carreiras literárias na década de 1930, a respeito desse processo. Esses intelectuais possuem a consciência, conforme Luís Bueno ${ }^{18}$, da 
condição subdesenvolvida e atrasada da sociedade brasileira, o que implica na construção de uma prosa romanesca em que a realidade é figurada a partir de um traço de negatividade presente tanto na estrutura social como numa mentalidade equivocada. Portanto, o progresso se faz presente de modo implícito na cena de Carlota, e o Grotão se torna o avesso da nova dinâmica histórica do Brasil.

A primeira parte da citação revela a própria fragmentação e o descentramento da figura do narrador. Durante a descrição das ações de Carlota, existe uma interrupção materializada nas reticências que demonstram um não dito, ou seja, o próprio discurso do narrador assume um caráter de dilaceramento ao assumir as omissões voluntárias que se inscrevem no seu enunciado pela marcação desse tipo de pontuação, espalhada em várias partes do romance; ou mesmo, como afirmam Wander Melo Miranda e Josalba Fabiana do Santos, pelos seus silêncios e lacunas os quais representam tanto os interditos familiares como a hesitação em recordar e esquecer completamente o passado.

A figura desse narrador lacunar, vacilante, possibilita o descentramento e a emergências das diversas temporalidades, tal como já foi evidenciado na parte relativa ao Comendador e agora ligado à visão de Carlota sobre sua terra. Desse modo, A menina morta se configura como uma espécie de epopéia negativa, nos termos de Adorno ${ }^{19}$, capaz de focalizar esse passado traumático e pesado - atravessado por múltiplas temporalidades - que revela um momento de dessubjetivação devido aos horrores perpetrados pela experiência vivida sob a forma da dominação patriarcal. Como no início do segundo trecho, as recordações mortais de Carlota também se inscrevem nas ruínas da espacialidade. $\mathrm{O}$ grau de negatividade presente nessas últimas duas passagens demonstra o momento em que Carlota, seguindo o pensamento de Adorno, liquida a si mesmo e a própria fazenda.

O foco de Carlota sobre a decadência dos campos de cultivo e da própria casa se caracteriza por forte traço melancólico decorrente da presença da violência traumática. Melancolia e alegoria se articulam para configurar aquilo Walter Benjamin denomina de "olhar saturnino" 20 . A ruína, presente na última citação, materializa esse ponto de vista, na medida em que ela potencializa a fragmentação do sentido -, ou seja, a arbitrariedade da língua e a perda de um referente total -, a historicidade e transitoriedade do mundo. Esses elementos, como afirma Jeanne Marie Gagnebin, não são uma simples fruição do estado de melancolia; ao contrário, revelam um dilaceramento do sentido capaz de construir uma "interpretação (que) consiste neste movimento de fragmentação e de desestruturação da enganosa totalidade histórica" 21 .

A melancolia se detém nos escombros dos campos de plantio do café; nos farrapos presentes nos caminhos e nas estradas; nas ruínas das flores, das árvores e da terra. Todos esses elementos evidenciam a ação corrosiva da história e a decadência de um sistema que permanece apenas como resíduo. A morte, desse modo, é constitutiva do real traumático e, por conseguinte, da melancolia, para cujo enfoque psicanalítico, de acordo com Freud ${ }^{22}$, a sua manifestação se relaciona a uma perda da ordem do inconsciente contrário, portanto, ao luto, que é reflexo de uma perda real, consciente - e que resulta numa intensa atividade crítica.

Retornando a última citação, o ponto de vista de Carlota possui esse caráter de alta criticidade a respeito da paisagem, uma vez que ela sente alegria, ou prazer triste, em ver a corrosão e a decadência das coisas, chegando até a caminhar por cima das plantas mortas a fim de espalhá-las pelos caminhos. A personagem, ao andar pela fazenda, contribui para disseminar a morte pelo espaço e, por conseguinte, pelo próprio sistema familiar. Desse modo, a atividade crítica do Eu constrói uma mirada sobre a propriedade 
como um cadáver, cujos restos e resíduos da espacialidade são metaforizados pelas gotas de sangue, demonstrando a sua finitude.

A morta da fazenda se estende ao patriarcalismo, cujas estruturas econômicas e sociais também sangram, o que revela a crise e a decadência dos seus dispositivos de verdade que legitimam os papéis, os espaços e as divisões de gênero, bem como o poder do pater familias. É importante observar que a perspectiva melancólica se projeta também no romance Repouso:

Encosta acima e de todos os outros lados, só havia terras ao abandono. Não se via nem mesmo sinais de antigo cultivo. Apenas deixara a destruição da floresta, que vinha até o lugar agora ocupado pelas casas das cidades, e da qual eram aquelas árvores os últimos remanescentes.

As plantas que se espalhavam em redor delas eram selvagens, apesar de terem sido outrora plantadas pelos homens. Os pedaços de muros que se levantam aqui e ali, arruinados, já não cercavam propriedades, não formavam um desenho simétrico, e seguiam ao acaso, esquecido de sua finalidade de outros tempos, sem nunca se encontrarem. ${ }^{23}$

Nesta passagem, há uma diferença em relação à perspectiva de $A$ menina morta. A descrição da decadência dos campos de cultivo apresenta uma oposição entre natureza e sociedade - no caso a vida social e econômica dos latifúndios brasileiros. Associada a imagem da ruína e do resíduo, a natureza passa a ter contornos selvagens, sem a presença ordenadora do trabalho do homem, avançando desordenadamente sobre as construções e as plantações abandonadas. Assim, o ponto de vista melancólico não apenas focaliza a finitude do mundo patriarcal, mas também identifica na natureza um elemento fantasmagórico, como se fosse uma espécie de alteridade.

Esse romance narra a história dos primos Dodôte e Urbano que, na infância, tiveram o seu casamento marcado pelas respectivas famílias. Entretanto, Urbano quebrou a promessa, se casando com outra mulher e se mudando para a cidade grande. Ao passo que Dodôte permaneceu na fazenda de sua família e, após a morte do pai e da mãe e da crise financeira da sua propriedade rural, ela se transfere, junto aos seus avós, para a casa da Ponte, localizada em uma pequena cidade interiorana. Depois da morte da mulher de Urbano, ele retorna para essa pequena cidade, onde o projeto inicial de matrimônio dos primos é retomado pela avó de Dodôte. O casamento se concretiza, mas se torna uma prisão para o casal, de modo que ambos se sentem prisioneiros dessa relação. Há, portanto, a imposição de uma violência de ordem simbólica sobre os personagens.

No entanto, a crise dessas formas de relações expõe a fragilidade dos laços e valores culturais e o grau de repressão que são submetidos os homens e as mulheres. É importante observar que os atos culturais, segundo Freud ${ }^{24}$, tem a finalidade de impor limitações às manifestações do libido - cuja realização é permitida no seio da família e nas relações humanas de amizade e de trabalho - e do instinto de destruição para construir a sociedade. Com isso, o processo cultural forma uma espécie de Super-eu coletivo que atua de modo a criar restrições aos instintos libidinais, a fim de contribuir para a formação de um dos aspectos do princípio de felicidade: a construção de vínculos entre os seres humanos capazes de uni-los em um grupo, comunidade ou sociedade. Contudo, essa ética gregária implica na alta repressão da libido sexual, o que produz a emergência de sintomas relacionados principalmente, segundo Freud, com o sentimento de culpa. 
Pode-se pensar numa correlação entre o mal-estar decorrente dos atos restritivos da cultura e a melancolia, na medida em que esta surge como decorrência de uma perda sem concretude no mundo real. Ou seja, a imposição dessa ética comunitária retira do sujeito a possibilidade de satisfazer o princípio de prazer individual. Há uma precariedade do sujeito que resulta de uma experiência coletiva baseada na violência presente, de um lado, nas repressões libidinais e, de outro, na delimitação de papéis sociais. Na última passagem, a decadência dos campos e construções revela a morte não apenas de uma configuração social e econômica, mas também do próprio sentido ordenador dessa cultura que é invadido pela natureza desordenada. Portanto, existe a noção de uma perda coletiva que não é superada no momento da enunciação ${ }^{25}$.

A precariedade do sujeito se evidencia na figura de Urbano. Prisioneiro de uma ética familiar que decide o seu destino, o personagem sai pelas ruas "disposto para a evasão"26 e acaba entrando numa mata. A natureza é vista a partir de uma dimensão exuberante e grandiosa, livre das amarras da cultura:

Irregular, ilógica, hostil, cheia de clareiras confusas e de cerrados espessos, distribuídos em desordem, emaranhados pelos cipós e pelas touceiras de espinhos, ora abria-se em pequenino jardim, atapetado de flores frágeis e ingênuas, ora erguia-se vertiginosamente em muralhas rugosas, impenetráveis, de pesados troncos escuros, cujas raízes se entrelaçavam como serpentes em luta. E surgiam as orquídeas sangrentas ou lutuosas, penduradas muito alto, repugnantes ou soberbas, mas sempre estranhas e surpreendentes. ${ }^{27}$

- Aqui longe de tudo, no meio desta fermentação, deste crescimento sem medida, desta guerra encoberta e implacável, eu poderei viver de acordo comigo mesmo, sem hipocrisia e sem escravidão. ${ }^{28}$

Urbano é o personagem marcadamente melancólico. Desde o fim de seu primeiro casamento e o seu retorno para a pequena cidade, ele vive como um espectro fantasmal que acolhe o matrimônio com sua prima Dodôte para salvar a crise financeira das famílias. Como bem explicou Gilberto Freyre, o mundo patriarcal se caracteriza por uma forte especialização dos sexos. Assim, diferentemente da primeira passagem de A menina morta, em que a exuberância do espaço natural representava grandeza da pátria, - a natureza, no romance Repouso, se torna um elemento de liberdade e materializa a imagem de um primitivismo anterior ao estabelecimento da cultura.

A natureza adquire uma dimensão grandiosa, construída por meio de traços expressivos, e que não se reduz às máscaras determinadas pela sociedade. O personagem sente esse espaço como um ambiente de liberdade. Há, com isso, um sentimento de oposição entre a mata e a cidade e, principalmente, a casa - local caracterizado como metáfora da prisão.

Segundo Letícia Malard ${ }^{29}$, se estabelece uma simbiose entre homem e natureza, na medida em que ela participa dos desejos do personagem. Na verdade, destinado a viver a máscara determinada pela sociedade patriarcal, Urbano observa a natureza como um lugar desprovido da teatralização da vida social. É nesse sentido que o ambiente, ao mesmo tempo em que materializa um índice de liberdade, reflete os seus desejos reprimidos pela imposição da máscara. Daí decorre a precariedade da vida subjetiva tanto de Urbano como de Dodôte, já que os papéis sociais são repressores dos seus desejos.

Os romances A menina morta e Repouso de Cornélio Penna apresentam a natureza como elementos relacionados com a crise do mundo patriarcal. Os sinais de decadência expõem a ação violenta dessa estrutura social mobilizada para a exploração do meio 
natural, da mão-de-obra escrava e para a delimitação dos papéis de gênero e de raça. A experiência dessa vida é evocada por meio de reminiscências que evidenciam fragmentos desse passado e cuja configuração narrativa se concretiza pela presença de um tipo de narrador lacunar que incorpora os interditos e as repressões para dentro do seu enunciado. Daí a formação de um olhar narrativo marcado pela melancolia para a qual o mundo passa a ser objeto de uma forte criticidade.

A construção dessa perspectiva melancólica se insere no romance $A$ menina morta para revelar as marcas da historicidade e da morte da fazenda do Grotão e, consequentemente, do patriarcalismo. A imagem da ruína se torna elemento estrutural, já que representa essa espacialidade como resquício de um mundo em completa decadência.

Esse processo de declínio também aparece no romance Repouso. Além de ser um resíduo de uma experiência pretérita, a natureza adquire uma dimensão primitiva, selvagem, na medida em que se opõe ao princípio ordenador da cultura. A sua oposição, desse modo, não ocorre apenas com relação à decadência da vida material, mas diz respeito às máscaras familiares que reprimem os desejos das personagens.

A configuração desse mundo aponta para a presença de eventos traumáticos relacionados com as vivências do patriarcalismo brasileiro. A precariedade desses sujeitos melancólicos decorre de ações culturais violentas capazes de embaralharem a noção de temporalidade, introduzindo, com isso, um passado que não passa, que revela uma obscuridade, como quer Agamben ${ }^{30}$, e que permanece como um peso insuportável no presente da enunciação.

Résumé: le travail a comme but l'analyser la présence de la nature dans les romans A menina morta et Repouso, écrits par Cornélio Penna. Le point de vue se fonde a partir de la perspective par laquelle cette deux oeuvres racontent les événements violents et traumatiques liés au déclin du monde patriarcal. Ainsi, la décadence du patriarcalisme est représentée par la nature qui apparaît dans un état d'abandon. De cette manière, il y a un regard mélancolique par lequel l'espace acquiert une dimension humaine, parce que la décadence montre le déclin du système sociale et économique de la famille patriarcale.

Mots-clé: Cornélio Penna; la nature;la mélancolie.

\section{Referências Bibliográficas}

ADORNO, Theodor. Posição do narrador no romance contemporâneo. In: ADORNO, Theodor. Notas de literatura I, trad. Jorge de Almeida. São Paulo: Duas cidades; Ed. 34, 2003. p.55-63.

AGAMBEN, Giorgio. O que é contemporâneo. In: O que é contemporâneo $e$ outros ensaios, trad. Vinícius Nicastro Honesko. Chapecó, SC.: Argos, 2009. P. 55-73 
AGAMBEN, Giorgio. O que resta de Auschwitz: o arquivo e a testemunha (Homo Sacer III), trad. Selvino J. Assmann. São Paulo: Boitempo, 2008. P. 175.

ANDRADE, Mario. Nota preliminar a Dois romances de Nico Horta. In: PENNA, Cornélio. Romances completos. Rio de Janeiro: José Aguilar, 1958. p.171-175.

BENJAMIN, Walter. Magia e técnica, arte e política: ensaios sobre literatura e história da cultura, trad. Sérgio Paulo Rouanet. São Paulo: Brasiliense, 1994. Obras escolhidas, Vol I. p. 253.

BENJAMIN, Walter. Origem do drama trágico alemão, trad. João Barrento. Belo Horizonte: Autêntica Editora, 2011. P.333.

BUENO, Luís. Uma história do romance de 30. São Paulo: Edusp, 2006. P. 707.

CANDIDO, Antonio. Literatura e subdesenvolvimento. In: CANDIDO, Antonio. A educação pela noite. Rio de Janeiro: Ouro sobre Azul, 2006. P. 169-196.

DIDI-HUBERMAN, Georges. Sobrevivência dos vaga-lumes, trad. Vera Casa Nova e Márcia Arbex . Belo Horizonte: Editora UFMG, 2011. P. 160.

FOUCAULT, Michel. A microfísica do poder, trad. Roberto Machado. Rio de Janeiro: Edições Graal, 1979. P. 295.

FREUD, Sigmund. O mal-estar na civilização, trad. Paulo César de Souza. São Paulo: Penguin Classics Companhia das Letras, 2011. P. 93.

FREUD, Sigmund. Luto e melancolia. In: Introdução ao narcisismo: ensaios de metapsicologia e outros textos, trad. Paulo César de Souza. São Paulo: Companhia das Letras, 20010. V. 12. P. 171-194.

FREYRE, Gilberto. Sobrados e mucambos: decadência do patriarcado rural e desenvolvimento do urbano. 15ª Edição. São Paulo: Global, 2004.

GAGNEBIN, Jeanne Marie. História e narração em Walter Benjamin. $2^{\mathrm{a}}$ Edição. E São Paulo: Perspectiva, 2009. P. 968. P. 114.

GAGNEBIN, Jeanne Marie. Verdade e memória do passado. In: GAGNEBIN, Jeanne Marie. Lembrar, escrever, esquecer. São Paulo: Ed. 34, 2006. P. 39-47.

GINZBURG, Jaime. Literatura brasileira: Autoritarismo, Violência, Melancolia. In: GINZBURG, Jaime. Crítica em tempos de violência. São Paulo:EDUSP, 2012. P. 173187.

HOLANDA, Sérgio Buarque de. Raízes do Brasil. Rio de Janeiro: J. Olympio, 1976. P. 154.

MIRANDA, Wander Melo. As casas assassinadas. In: MIRANDA, Wander Melo. Nações literárias. Cotia, SP: Ateliê Editorial, 2010. P. 67-76.

LIMA, Luís Costa. O romance em Cornélio Penna. $2^{\text {a }}$ Edição. Belo Horizonte: Editora UFMG, 2005. P. 231. 
MALARD, Letícia. Um antiquário apaixonado. In: Penna, Cornélio. Repouso. Rio de Janeiro: Artium, 1998. p. xi-xxviii.

OTTE, Georg. Linha, choque e mônada: tempo e espaço na obra tardia de Walter Benjamin. Tese (Doutorado em Estudos Literários) - Faculdade de Letras, Universidade Federal de Minas Gerais, Belo Horizonte, 1994. P. 280.

PENNA, Cornélio. A menina morta. Curitiba: RM Editores, 2009. P. 624.

PENNA, Cornélio. Repouso. Rio de Janeiro: Artium, 1998. P. 388.

RODRIGUES, André Luís. Fraturas no olhar: realidade e representação em Cornélio Penna. Tese (Doutorado em Literatura Brasileira) - Faculdade de Filosofia, Letras e Ciências Humanas, Universidade de São Paulo, São Paulo, 2006. P. 273.

RUFINONI, Simone Rossinetti. Favor e melancolia: um estudo sobre A menina morta. São Paulo: Nankin; Edusp, 2010. P. 200.

SANTOS, Josalba Fabiana dos. Fronteiras da nação em Cornélio Penna. Tese (Doutorado em Estudo Literários) - Faculdade de Letras, Universidade Federal de Minas Gerais, Belo Horizonte, 2004. P. 262.

SELIGMANN-SILVA, Márcio. A história como trauma. In: NESTROVSKI, Arthur e SELIGMANN-SILVA, Márcio. Catástrofe e representação: ensaios. São Paulo: Escuta, 2000. P. 73-98.

SELIGMANN-SILVA. Márcio. Catástrofe, história e memória em Walter Benjamin e Chris Marker: a escritura da memória. In: SELIGMANN-SILVA, Márcio (org.). História, memória, literatura: o testemunho na Era das catástrofes. Campinas, SP: Ed. Da Unicamp, 2003. P. 391-417.

SELIGMANN-SILVA, Márcio. Apresentação da questão. In: SELIGMANN-SILVA, Márcio (Org.). História, memória, literatura: o testemunho na Era das catástrofes. Campinas, SP: Ed. Da Unicamp, 2003. P. 45-58

\section{Notas}

174 .

2

3 178.

Benjamin, 1994.

SELIGMANN-SILVA. Apresentação da questão, p. 49.

GINZBURG. Literatura Brasileira: Autoritarismo, Violência, Melancolia, p.

GAGNEBIN. Verdade e memória do passado, p. 44

OTTE. Linha, choque e mônada: tempo e espaço na obra tardia de Walter

6 OTTE. Linha, choque e mônada: tempo e espaço na obra tardia de Walter Benjamin, 1994.

$7 \quad$ PENNA. A menina morta, p. 23

8 CANDIDO. Literatura e subdesenvolvimento, p. 171. 
PENNA. A menina morta, p. 24

PENNA. A menina morta, p. 25

HOLANDA. Raízes do Brasil, 1976.

FREYRE. Sobrados e mucambos, 2004.

PENNA. A menina morta, p. 184.

PENNA. A menina morta, p.107/108.

PENNA. A menina morta, p. 614.

PENNA. A menina morta, p. 614/615.

SANTOS. Fronteiras da nação em Cornélio Penna, 2004.

BUENO. Uma história do romance de 30, 2006.

ADORNO. A posição do narrador no romance contemporâneo, 2003.

BENJAMIN. Origem do drama tráfico alemão, p. 191.

GAGNEBIN. História e narração em Walter Benjamin, p. 43.

FREUD. Luto e melancolia, 2010.

PENNA. Repouso, p. 182.

FREUD. O mal-estar na civilização, 2011.

GINZBURG. Literatura Brasileira: Autoritarismo, Violência, Melancolia,

PENNA. Repouso, p. 164.

PENNA. Repouso. P. 164/165.

PENNA. Repouso. P. 166.

MALARD. Um antiquário Apaixonado, 1998.

AGAMBEN. O que é contemporâneo, 2009. 